\title{
Árboles del Valle Central de Costa Rica: reproducción del Guácimo ternero (Guazuma ulmifolia Lam.)
}

\section{Trees of the Central Valley of Costa Rica: reproduction of Guácimo ternero (Guazuma ulmifolia Lam.)}

\author{
Freddy Rojas-Rodríguez • Gustavo Torres-Córdoba²
}

\section{Resumen}

Se presenta una breve descripción del árbol guácimo ternero (Guazuma ulmifolia Lam.), incluyendo información sobre fenología como base para la recolección de frutos, el manejo de las semillas, la viverización y el proceso de germinación.

Palabras clave: Fenología, manejo de semillas, viverización, germinación, árboles.

\section{Abstract}

The following issue presents a brief description about the "Guácimo ternero" tree (Guazuma ulmifolia Lam.), including information about its phenology which directly relates to fruit recollection, seed treatment, nursery, and germination processes.

Keywords: Phenology, seeds treatments, management at nursery, germination, trees.

1. Consultor Independiente; Cartago, Costa Rica; freddyrojasrodriguez@gmail.com

2. Tecnológico de Costa Rica, Escuela de Ingeniería Forestal;

Cartago, Costa Rica; gtorres@tec.ac.cr; (+506) 2550- 2039
Recibido: 29/04/2019

Aceptado: 24/05/2019

Publicado: 28/06/2019

DOI: 10.18845/rfmk.v16i39.4431 


\section{Taxonomía}

Nombre científico: Guazuma ulmifolia Lam.

Nombre común: Guácimo ternero, Guácimo.

Familia: Sterculiaceae.

Origen: Nativa.

Distribución en el mundo: Desde México a través de Centro América hasta Paraguay, incluyendo las islas caribeñas desde Cuba hasta Trinidad y Tobago.

Distribución en Costa Rica: Común en charrales y potreros de ambas vertientes.

\section{Descripción}

Árbol mediano, semicaducifolio, de copa umbeliforme. Su fuste es de ramaje muy extendido, horizontal y hasta colgante, siempre verde y ramificado desde la base. La corteza es agrietada, acanalada, áspera, café oscuro, gruesa, internamente de color rosado y muy mucilaginosa

Las hojas son simples, alternas, con peciolos cortos, oblongo lanceoladas, borde aserrado, de 6 a $12 \mathrm{~cm}$ de

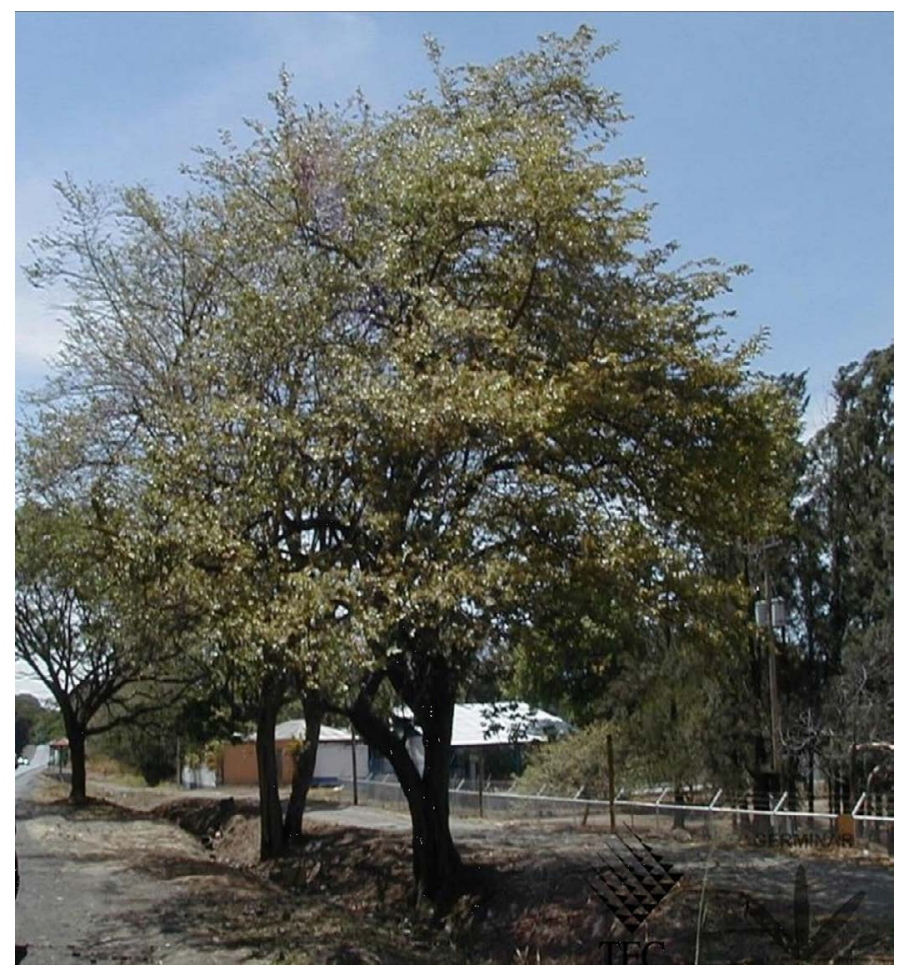

Figura 1. Perfil de Guácimo ternero.

Figure 1. Profile of "Guácimo ternero" tree. largo y de 2 a $6 \mathrm{~cm}$ de ancho, acuminada, de color verde oscuro en el haz y verde amarillento en el envés y con muchas pubescencias pequeñas.

Sus flores son fragantes, con pétalos de color amarillo, estambres blancos; nacen en grupos en las axilas de las hojas, pequeñas y muy visitadas por las abejas melíferas.

El fruto es seco indehiscente, tipo cápsula, con grietas, de forma ovoide, con una pulpa amarilla y dulce muy apetecida por el ganado, de 2,5 cm de largo y de 1,5 $\mathrm{cm}$ de grosor. Externamente es de aspecto superficial verrugoso y de color negro al madurar.

Las semillas son de forma ovoide, globosa o redondeada, de 2,0 a 2,5 mm de largo (microsperma), testa café claro ligeramente rugosa, opaca y coriácea [1].

Su madera es de color marrón claro y el duramen marrón rosado, es fácil de trabajar y usada en carpintería, ebanistería y construcción de interiores [2]. Esta es suave, poco compacta y de buena durabilidad cuando es protegida de la lluvia o humedad [3].

\section{Dendrofenocronograma}

En cuadro 1 se presenta a continuación información fenológica de Guácimo ternero en el Valle Central de Costa Rica.

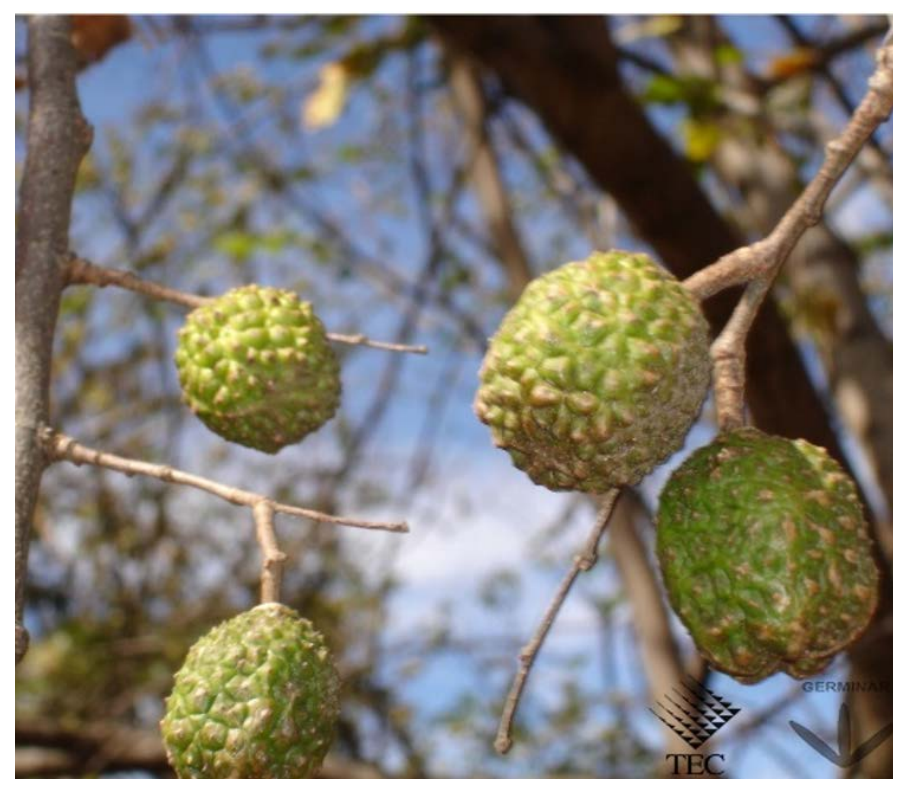

Figura 2. Fruto de Guácimo ternero.

Figure 2. Fruit of "Guácimo ternero" tree. 
Cuadro 1. Dendrofenocronograma del Guácimo ternero en el Valle Central, Costa Rica.

Table 1. Tree phenology through time in "Guácimo ternero", Central Valley, Costa Rica.

\begin{tabular}{|c|c|c|c|c|c|c|c|c|c|c|c|c|}
\hline \multirow{2}{*}{ Características } & \multicolumn{12}{|c|}{ Meses del año } \\
\hline & $\mathrm{E}$ & $F$ & $M$ & A & $\mathrm{M}$ & $\mathrm{J}$ & $\mathrm{J}$ & A & $S$ & 0 & $\mathrm{~N}$ & $\mathrm{D}$ \\
\hline \multicolumn{13}{|l|}{ Hojas } \\
\hline \multicolumn{13}{|l|}{ Flores } \\
\hline Frutos verdes & & & & & & & & & & & & \\
\hline Frutos maduros & & & & & & & & & & & & \\
\hline
\end{tabular}

\section{Manejo de semilla y viverización}

Los frutos tipo folículo guácimo se recolectan en los meses de enero a marzo en el Valle Central de Costa Rica. La madurez de sus frutos se reconoce por su color oscuro y su momento de dispersión barócora y endozóocora. La recolección preferiblemente debe hacerse directamente del suelo [1].

Para su procesamiento, los frutos deben ser cortarlos por los extremos para permitir la liberación de las semillas, las cuales en caso de ser almacenadas debe permanecer en cuarto frío, a una temperatura de 3 - 10 ${ }^{\circ} \mathrm{C}$, una humedad relativa de $10 \%$ y en bolsas selladas herméticamente [1].

Las semillas se pueden sembrar por el método del voleo en un sustrato a base de tierra más arena. Éstas se deben cubrir apenas superficialmente y su germinación se experimenta entre 7 y 14 días después de la siembra. Su porcentaje de germinación, dependiendo de la calidad de la semilla es menor al $60 \%$ y se puede llegar a obtener un total de 213106 semillas por kilo [1].

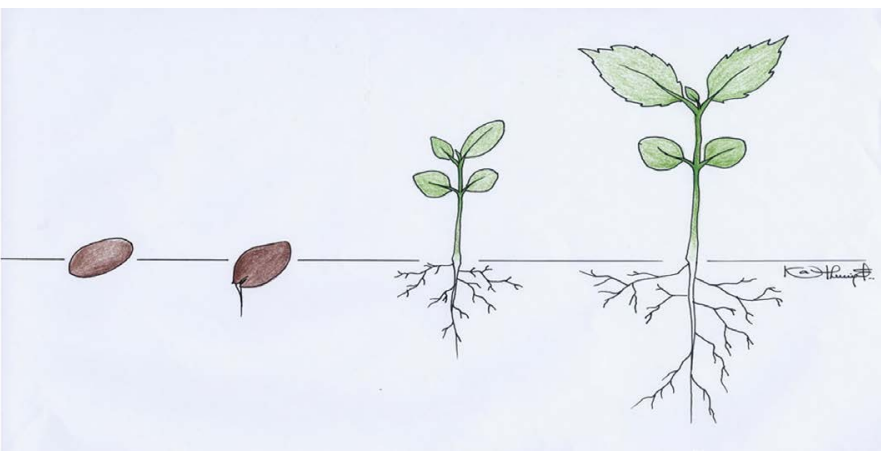

Figure 3. Proceso de germinación del Guácimo ternero.

Figure 3. Seed germination of "Guácimo ternero" tree.
Las plántulas se encuentran listas para su repique o trasplante, bajo el sistema de producción en bolsa plástica, pote biodegradable $\mathrm{o}$ contenedor aproximadamente a las dos semanas posteriores a la germinación. Se ha dado la presencia de manchas circulares pardo negruzco en el follaje de hasta 0,8 $\mathrm{cm}$ de diámetro. En cuanto al mantenimiento, no es recomendable aplicar sombra por un periodo no mayor a los 14 días, y se recomienda incorporar en el sustrato fertilización química u orgánica para acelerar el crecimiento de dichas plántulas [1].

\section{Proceso de germinación}

El tipo de germinación del guácimo ternero es epígea, según la figura 3.

\section{Referencias}

[1] Torres, C., Carvajal, D., Rojas, F. y Arguedas M. Reproducción de especies arbóreas y arbustivas de la región central de Costa Rica (Germinar 2.0). Cartago, Costa Rica: Instituto Tecnológico de Costa Rica. Recuperado de: https:// www.tec.ac.cr/sites/default/files/media/swf/Germinar_2/ Germinar-2.swf. 2011

[2] CATIE. Especies para leña: Arbustos y árboles para la producción de energía. Proyecto Leña y Fuentes. CATIE, National Academy of Science. Talleres gráficos Trejos Hnos. p 142. 1984

[3] Lorenzi, H. Árvores brasileiras: Manual de identifiçao e cultivo de plantas arbóreas nativas do Brasil. Editorla Plantarum. Sao Paulo, Brasil. 1992. p 327. 